\title{
Mechanism of catalytic hydropyrolysis of sedimentary organic matter with $\mathrm{MoS}_{2}$
}

\author{
He Kun ${ }^{1,2}$, Zhang Shuichang ${ }^{1,2 *}$, Mi Jingkui ${ }^{1,2}$, Chen Jianping ${ }^{1,2}$ and \\ Cheng Lei ${ }^{1,2}$
} ${ }^{1}$ Petroleum Geology Research and Central Laboratory, Research Institute of Petroleum Exploration and Development
(RIPED), PetroChina, Beijing 100083, China

${ }^{2}$ CNPC Key Laboratories for Petroleum Geochemistry, Beijing 100083, China

(C) China University of Petroleum (Beijing) and Springer-Verlag Berlin Heidelberg 2011

\begin{abstract}
MoS}_{2}$ was used as an efficient catalyst for hydropyrolysis (Hypy) of three samples of sedimentary organic matter with different maturities. Through comparison with Soxhlet extraction (SE), it was found that $\mathrm{MoS}_{2}$ catalytic Hypy can remarkably promote the yields of total chloroform extracts, saturates, aromatics, hopanes and steranes. In addition, the difference of biomarker parameters indicated that isomerization of covalently-bound biomarkers is much more difficult than their free counterparts. Meanwhile, the high conversion of total organic carbon (TOC) in $\mathrm{MoS}_{2}$ catalytic Hypy of organic matter proved that the presence of dispersed molybdenum sulfide accelerated the breaking of $\mathrm{C}-\mathrm{C}$ bonds and the release of hydrocarbons. To address the catalytic mechanism, a series of control experiments based on free Hypy and catalytic Hypy were conducted. The results showed that the calculated atomic ratio of carbon conversion/hydrogen conversion for catalytic Hypy was much larger than the presumed value of $1 / 2$, indicating that intensive hydrogenation took place and significantly influenced the distribution of liquid products. Analysis of stable hydrogen isotope data, infrared spectra and $\mathrm{m} / \mathrm{z} 83$ ion chromatograph of the saturate fraction further confirmed this hypothesis. The difference of $S$ content changing $(\Delta S)$ between catalyst-free Hypy and catalytic Hypy, and the thermal characteristics of the catalyst, indicated that active $\mathrm{H}_{2} \mathrm{~S}$ was definitely generated and it probably initiated free radical reactions in the early stage of hydropyrolysis of organic matter.
\end{abstract}

Key words: Catalytic hydropyrolysis, molybdenum disulfide, kerogen, coal, Soxhlet extraction, biomarkers

\section{Introduction}

As a novel analysis technique, hydropyrolysis can give higher yields of extractable bitumen and biomarkers relative to conventional solvent extraction. Hydropyrolysis exhibits unique advantages in recovery of hydrocarbons and biomarker profiles, which are derived from formerly living organisms and used for maturation assessment, oil-source correlation and paleoesedimentary environment indication (Peters and Moldowan, 1993; Fu et al, 1991), especially when organic matter has suffered intensive thermal maturation, or post-depositional oxidation and biodegradation (Meredith et al, 2008). Meanwhile, it has been found that terpanes generated from kerogen or coal by hydropyrolysis can be more structurally representative of the bulk organic matter (Eglinton and Douglas, 1988; Kohnen et al, 1991; Russell et al, 2004; Lockhart et al, 2008). With these advantages, hydropyrolysis has received much attention and has been used

*Corresponding author. email: sczhang@petrochina.com.cn Received July 16, 2010 in the study of extraction of covalently-bound biomarkers and of coal liquefaction since it was developed (Snape et al, 1994; Love et al, 1995; Inukai, 1995; Ikenaga et al, 1997; Rocha et al, 1997).

Molybdenum disulfide, which is commonly used as a commercial catalyst in its various forms, usually shows good catalytic efficiency in several processes such as hydrodesulfurization and $\mathrm{CO}$ methanation reactions (Bevanente et al, 2002; Farag et al, 2009; Shi et al, 2009). To increase the liquid hydrocarbons and biomarkers yields in hydropyrolysis of coals or kerogens, most researchers introduce $\mathrm{MoS}_{2}$ as catalyst. Snape et al (1994) initially employed $\mathrm{MoS}_{2}$ as catalyst in fixed-bed hydropyrolysis of coals and oil shales, and obtained the yields of dichloromethane (DCM)-soluble oil of $>65 \%$ and overall conversion of $>85 \%$. Love et al (1995) found that hydropyrolysis of Göynük oil shale in the presence of dispersed molybdenum sulfide can obtain extremely high yields of DCM-soluble extracts and biomarkers including several hopanes, steranes and methyl steranes, compared to other approaches. Obviously, catalytic hydropyrolysis can 
remarkably promote the yields of both the liquid hydrocarbons and covalently-bound biomarkers. High hydrogen pressure $(>10 \mathrm{MPa})$ and the presence of well dispersed catalyst can accelerate both the cracking of C-C or C-S bonds and the hydrogenation reaction. Although considerable work has been done to investigate the effect of catalytic hydropyrolysis on the release of hydrocarbons and biomarkers, few studies discuss and address the catalytic mechanism of $\mathrm{MoS}_{2}$ in this process.

This paper first describes the effect of $\mathrm{MoS}_{2}$ hydropyrolysis in view of yields of liquid products in comparison with Soxhlet extraction (SE). Then to investigate the particular role of dispersed molybdenum sulphide played in catalytic hydropyrolysis, experiments with and without $\mathrm{MoS}_{2}$ catalyst were conducted. Subsequently, a catalytic mechanism of $\mathrm{MoS}_{2}$ is proposed, involving free radical reaction initiated by intermediate $\mathrm{H}_{2} \mathrm{~S}$ and catalytic hydrogenation via Lewis acid sites provided by Mo.

\section{Experimental}

\subsection{Samples and reagents}

Samples used in this study include a mature kerogen identified as type-III and two types of coals with different thermal maturities, their analytical data of vitrinite reflectance and solvent extracts are listed in Table 1. The type-III kerogen was isolated from pulverized mudstone, which is of Cretaceous age and originally located in the Shahezi Formation in the Songliao Basin, NE China. The depth and total organic carbon (TOC) of the original mudstone are $1,408.5 \mathrm{~m}$ and $3.14 \mathrm{wt} \%$. Two coals were collected from the Jurassic Fuxin formation in the Fuxin Basin (hereafter "Fuxin coal") and the Cretaceous Yingcheng formation in the Songliao Basin (hereafter "Yingcheng coal"), with TOC of $71 \mathrm{wt} \%$ and $67 \mathrm{wt} \%$ accordingly.

Hydrogen used in hydropyrolysis is of high-purity

Table 1 Products yields from Soxhlet extraction (SE) and catalytic hydropyrolysis (Hypy)

\begin{tabular}{|c|c|c|c|c|c|c|}
\hline \multirow{2}{*}{ Sample } & \multirow{2}{*}{ TOC $(\%)$} & \multirow{2}{*}{ Ro $(\%)$} & \multirow{2}{*}{ Method } & \multicolumn{3}{|c|}{ Yields, mg/(g initial sample) } \\
\hline & & & & Total extracts & Saturates & Aromatics \\
\hline \multirow{2}{*}{$\begin{array}{l}\text { Type-III } \\
\text { kerogen }\end{array}$} & \multirow{2}{*}{$3.14 *$} & \multirow{2}{*}{0.84} & SE & 12.3 & 0.75 & 1.3 \\
\hline & & & Cat. Hypy & 390.9 & 14.9 & 137.6 \\
\hline \multirow{2}{*}{ Fuxin coal } & \multirow{2}{*}{71.24} & \multirow{2}{*}{0.55} & SE & 7.7 & 0.8 & 0.7 \\
\hline & & & Cat. Hypy & 86.6 & 21.9 & 11.7 \\
\hline \multirow{2}{*}{$\begin{array}{l}\text { Yingcheng } \\
\text { coal }\end{array}$} & \multirow{2}{*}{67.00} & \multirow{2}{*}{1.02} & SE & 2.9 & $<0.1$ & 0.24 \\
\hline & & & Cat. Hypy & 126.0 & 2.9 & 20.3 \\
\hline
\end{tabular}

Notes: * This TOC value belongs to the original mudstone of the type-III kerogen.

The unit $\mathrm{mg} /(\mathrm{g}$ initial sample) means the quantity of products generated from 1 gram initial sample. SE and Cat. Hypy refer to solvent extraction of organic matter and catalytic hydropyrolysis with dispersed molybdenum sulphide correspondingly. Ro means vitrinite reflectance of the coal.

with $\delta \mathrm{D}$ value of $-86.525 \%$. Solvents such as chloroform, DCM, hexane and ethanol are all of analytical grade and were distilled to remove impurities before use in extraction. $\left(\mathrm{NH}_{4}\right)_{2} \mathrm{MoO}_{4} \cdot 4 \mathrm{H}_{2} \mathrm{O}$ and $\left(\mathrm{NH}_{4}\right)_{2} \mathrm{~S}$, which were used for preparation of the catalyst precursor, are analytical grade and in concentration of $8 \mathrm{wt} \%$ respectively. Water used in experiments is distilled water.

\subsection{Catalytic hydropyrolysis}

\subsubsection{Preparation and loading of catalyst}

$\left(\mathrm{NH}_{4}\right)_{2} \mathrm{MoS}_{4}$, the catalyst precursor in this work, was synthesized through an aqueous reaction. Firstly, $\left(\mathrm{NH}_{4}\right)_{2} \mathrm{MoO}_{4} \cdot 4 \mathrm{H}_{2} \mathrm{O}$ was slowly added into $8 \%\left(\mathrm{NH}_{4}\right)_{2} \mathrm{~S}$ solution in an ice bath and stirred for $20 \mathrm{~min}$. Then the mixed solution was filtered and the solid product was dried to obtain the catalyst precursor. The XRD pattern of the catalyst precursor is shown in Fig. 1. Unfortunately only poor quality patterns are observed, because the bulk precursor is mainly composed of amorphous $\left(\mathrm{NH}_{4}\right)_{2} \mathrm{MoS}_{4},\left(\mathrm{NH}_{4}\right)_{2} \mathrm{MoS}_{2} \mathrm{O}_{2}$,
$\left(\mathrm{NH}_{4}\right)_{2} \mathrm{MoO}_{4}$ and a small amount of crystal $\operatorname{MoS}_{\mathrm{x}}(x \leq 2)$. Actually, some literature has proved that $\left(\mathrm{NH}_{4}\right)_{2} \mathrm{MoS}_{4}$ or $\left(\mathrm{NH}_{4}\right)_{2} \mathrm{MoO}_{2} \mathrm{~S}_{2}$ would be decomposed to active $\mathrm{MoS}_{2}$ when heated above $250{ }^{\circ} \mathrm{C}$ in the presence of $\mathrm{H}_{2}$ (Zelenski and Dorhout, 1998; Boone et al, 2000). Hence, in view of the temperature program used in this study, $\mathrm{MoS}_{2}$ can be reasonably considered as the catalyst during the main stage of catalytic hydropyrolysis. In a typical catalytic process, the catalyst precursors are firstly loaded on organic matter by a rotary evaporator.

\subsubsection{Hydropyrolysis experiments}

All the hydropyrolysis experiments were conducted on a Hypy apparatus made by Strata Technology Ltd.(UK), as shown in Fig. 2. In a typical procedure, the pyrolysates were collected on the pre-extracted silica gel loaded in the collection tube, which was entirely immerged in liquid nitrogen. The pressure and flow rate of $\mathrm{H}_{2}$ were set at $10 \mathrm{MPa}$ and $4 \mathrm{~L} / \mathrm{min}$ respectively. The temperature was programmed as follows: firstly it was heated from ambient temperature to $250{ }^{\circ} \mathrm{C}$ at $300{ }^{\circ} \mathrm{C} / \mathrm{min}$, then to $520{ }^{\circ} \mathrm{C}$ at $5{ }^{\circ} \mathrm{C} / \mathrm{min}$ and kept 


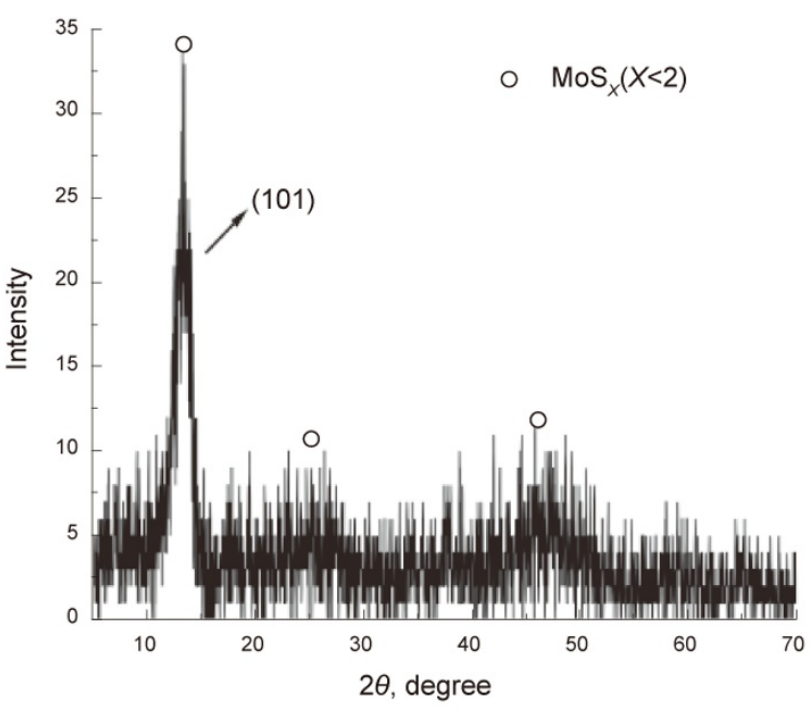

Fig. 1 The XRD pattern of the catalyst precursor

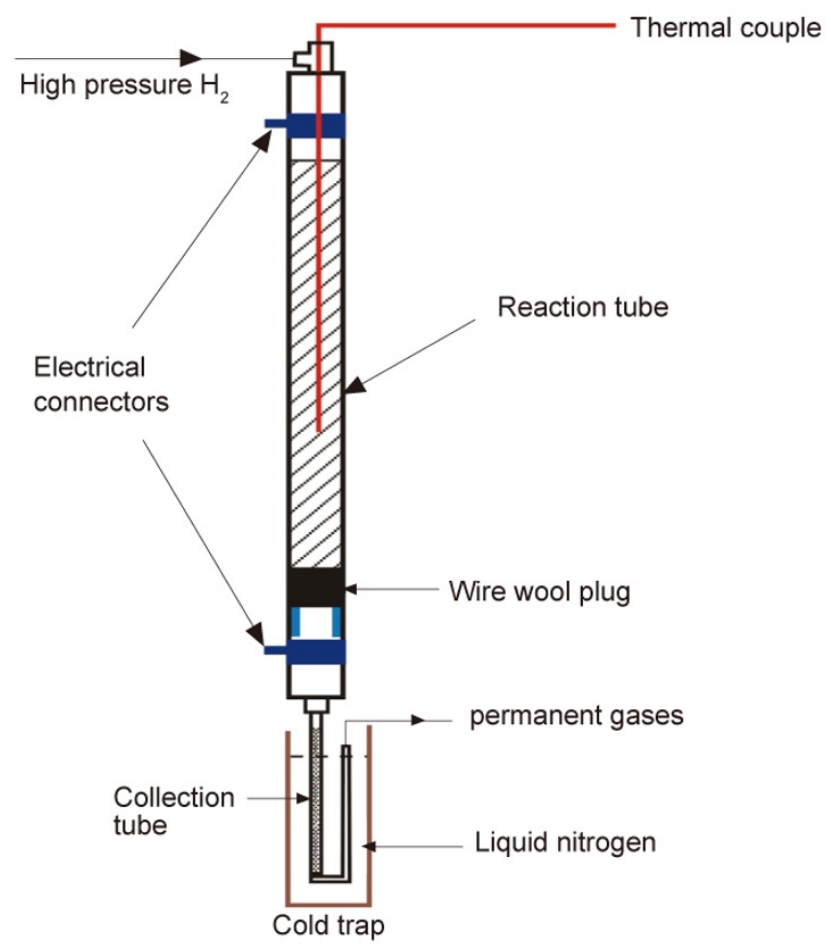

Fig. 2 Schematic representation of the hydropyrolysis apparatus

at $520{ }^{\circ} \mathrm{C}$ for $5 \mathrm{~min}$. After the reaction, the silica gel was collected and extracted with chloroform to obtain the liquid products for analysis.

\subsubsection{Analysis method}

The separation and yield determination of four fractions of liquid products were performed by a Chinese standard analysis method (SY/T 5119-2008). The saturates were analyzed by gas chromatography-mass spectrometry (GC-MS) in full scan mode, which was performed on a Trace GC Ultra gas chromatograph interfaced to a DSQII mass spectrometer (EI mode, $70 \mathrm{eV})($ Thermo Co. Ltd., USA). Prior to the GCMS analysis, a sterane standard $(5 \alpha(\mathrm{H})$-androstane $)$ was added into saturates fractions to determine the concentration of hopanes and steranes. Elements content and stable hydrogen isotope values $(\delta \mathrm{D})$ of samples were respectively determined by using a Vario Micro Cube elemental analyzer (Elemantar, Germany) and a Flash EA 1112 Series stable isotope massspectrometry instrument (Thermo Co. Ltd., USA). The X-ray diffraction (XRD) characterization of the catalyst precursor and the infrared (IR) spectrum detection of the samples were conducted on a TTR III X-ray diffractometer (Rigaku Corporation, Japan) and a Nicolet continuum Micro-IR spectrometer respectively ( Thermo Co. Ltd., USA).

\section{Results and discussion}

\subsection{Yields of extracts and biomarkers}

To investigate the hydrocarbons yield of this novel catalytic hydropyrolysis technique, the yields of hydrocarbon and biomarker by catalytic hydropyrolysis (Hypy) were compared with that by the Soxhlet extraction (SE) and presented in Table 1. From the table, it can be found that the yields of total extracts, saturates and aromatics were significantly enhanced by catalytic Hypy. For Yingcheng coal, the yield of total extracts from catalytic Hypy was 43 times that from SE. For all the three types of samples, saturates from SE were all less than $1.0 \mathrm{mg} /(\mathrm{g}$ initial sample), whereas those from catalytic Hypy reached 14.9, 21.9 and $2.9 \mathrm{mg} /$ ( $\mathrm{g}$ initial sample) respectively. The significant increase of products yields might be attributed to the combined action of increasing temperature, high-pressure $\mathrm{H}_{2}$ and $\mathrm{MoS}_{2}$ catalyst. The combined action led to the cracking of C-C bonds and the generation of hydrocarbons. Actually, Behar and Vandenbroucke (1996) have studied the cracking of n-alkane at different temperatures and pressures through a confined system, and found that the conversion of $n-\mathrm{C}_{25}$ surprisingly exceeded $60 \%$ in an hour at $425{ }^{\circ} \mathrm{C}$ and $12 \mathrm{MPa}$ (Behar and Vandenbroucke, 1996). Another previous work (Sharma et al, 1998) has found that high temperature and hydrogen pressure $(15 \mathrm{MPa})$ in the hydroliquefaction of coal can accelerate the generation of liquid products, especially at high temperature. In catalytic Hypy, Fuxin coal generated a higher yield of saturates fraction than Yingcheng coal. This may be attributed to their different maturities, that is, relatively lowmatured Fuxin coal contains more aliphatic side chains in its molecular structure.

Table 2 lists the yields of several saturates hydrocarbon biomarkers obtained from SE and catalytic Hypy of two coals. In Soxhlet extraction (SE), the yields of biomarkers of highly-matured Yingcheng coal (Ro, 1.02) were lower than those of Fuxin coal (Ro, 0.55). This is accordance with that observed in bulk extracts. The reason might be that increasing thermal stress made those earlier formed large molecular biomarker hydrocarbons decomposed to form small molecular cycloalkanes and alkanes. Moreover, for Fuxin coal and Yingcheng coal, the yields of biomarkers were much higher from catalytic Hypy than from SE. This result indicates that catalytic Hypy provide a promising approach for both aliphatic fractions and biomarkers extraction from original sedimentary organic matter. 
Table 2 Yields of partial biomarkers from SE and catalytic Hypy (ug/g coal)

\begin{tabular}{cccccccccc}
\hline \multirow{2}{*}{ Sample } & Method & $\mathrm{Ts}$ & $\mathrm{Tm}$ & $\mathrm{C}_{29} 17 \alpha(\mathrm{H})$-hopa ne & $\mathrm{C} 29 \mathrm{Ts}$ & $\mathrm{C}_{30}$ hopa ne & $\mathrm{C}_{30}$ moretane & $\mathrm{C}_{29} \alpha \alpha \alpha$-sterane $(20 \mathrm{~S})$ & $\mathrm{C}_{29} \alpha \alpha \alpha-\mathrm{sterane}(20 \mathrm{R})$ \\
\hline \multirow{2}{*}{ Fuxin coal } & $\mathrm{SE}$ & 23.9 & 2.9 & 21.3 & 1.7 & 28.7 & 13.9 & 4.3 & 12.2 \\
& Cat. Hypy & 216.9 & 50.7 & 296.6 & 25.0 & 266.6 & 158.2 & 32.8 & 114.1 \\
\hline \multirow{2}{*}{ Yingcheng coal } & SE & 6.9 & 1.1 & 5.3 & 0.2 & 7.5 & 3.7 & 0.6 & 2.2 \\
& Cat. Hypy & 130.6 & 55.1 & 190.4 & 5.4 & 103.0 & 73.2 & 8.5 & 40.2 \\
\hline
\end{tabular}

Fig. 3 shows the $\mathrm{m} / \mathrm{z} 85$ mass chromatogram of saturated hydrocarbons from SE and Catalytic Hypy of Fuxin coal. The distribution of n-alkanes obtained from the two approaches differs significantly. The distribution of n-alkanes from SE exhibits an evident odd-carbonnumber predominance with an odd-even predominance (OEP) value of 1.64, which was calculated with the equation reported by Scalan and Smith (1970) when $i=23$. While from Catalytic Hypy, the distribution of n-alkanes shown in Fig. 3(b) exhibits an irregular distribution not an odd-carbonnumber predominance. This difference might be explained by the thermal evolution of coal and the free counterparts in catalytic Hypy, in which large amounts of n-alkanes without odd or even predominance were produced. In addition, the dominant distribution of n-alkanes was obviously transferred to that with large carbon number in comparison with Fig. 3 (a), indicating that aliphatic hydrocarbons with high carbon number were released from coal.
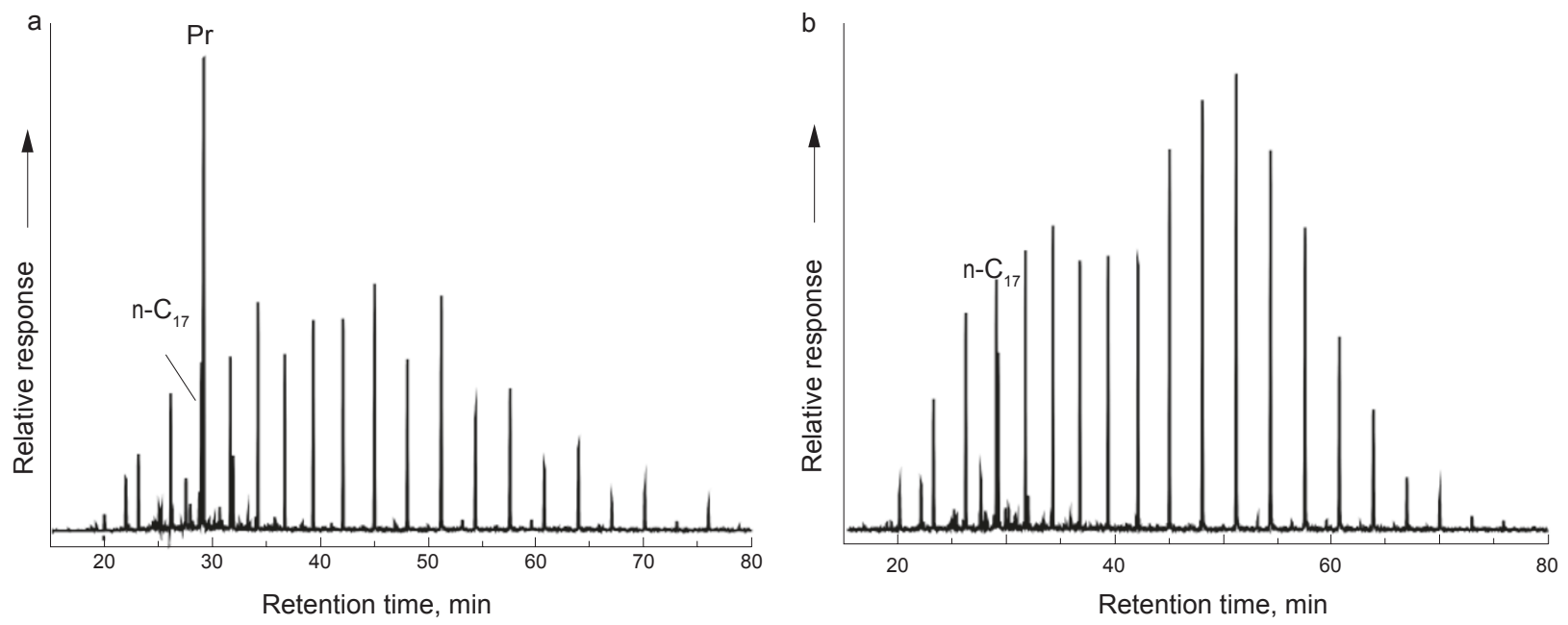

Fig. $3 \mathrm{M} / \mathrm{z} 85$ mass chromatograph of saturated hydrocarbons from (a) SE and (b) Catalytic Hypy of Fuxin coal

\subsection{Biomarker parameters}

The $\mathrm{m} / \mathrm{z} 191$ mass chromatographs of saturated hydrocarbons from SE and Catalytic Hypy of Fuxin coal and Yingcheng coal are shown in Fig. 4 and Fig. 5. It can be seen that saturates from Catalytic Hypy include almost all the hopanes gained from SE. Moreover, an additional compound was unexpectedly eluted closely prior to $\mathrm{C}_{27}$ $18 \alpha(\mathrm{H})$-trisnorhopane (Ts). Meanwhile, the distribution of hopane in the m/z 191 chromatograph from SE and Catalytic Hypy was different, i.e., the relative content of each isomer of hopanes from the two approaches was different. The biomarker parameters reflecting the maturation of coal samples were calculated by their peak areas in the $\mathrm{m} / \mathrm{z} 191$ mass chromatograph, and are shown in Table 3. For the two coals, the maturation reflected by the parameters of biomarker from SE was higher than that from Catalytic Hypy.
For instance, the conventional hopane ratios, Ts/(Ts+Tm) and $\mathrm{C}_{31} \alpha \beta 22 \mathrm{~S} /(22 \mathrm{~S}+22 \mathrm{R})$, are 0.86 and 0.56 for SE saturates product of Yingcheng coal, while these ratios for Cat. Hypy saturates product are only 0.70 and 0.41 accordingly. As mentioned above, the extracts from SE of coal represent the free hydrocarbon and non-hydrocarbon fractions formerly generated and sedimented in coal, while the products from Catlytic Hypy are released from the molecular structure of coal or kerogen and represent the hydrocarbon and nonhydrocarbon being bound by covalent bonds in the side chains of macromolecules of coal or kerogen. Hence the deviation of biomarker ratios indicates that the free and bound biomarkers experienced different isomerization. Indeed, it has been demonstrated that the isomerization (in ring and side chain) of kerogen-bound biomarkers is prohibited compared to that of the free phase (Russell et al, 2004; Lockhart et al, 2008). 

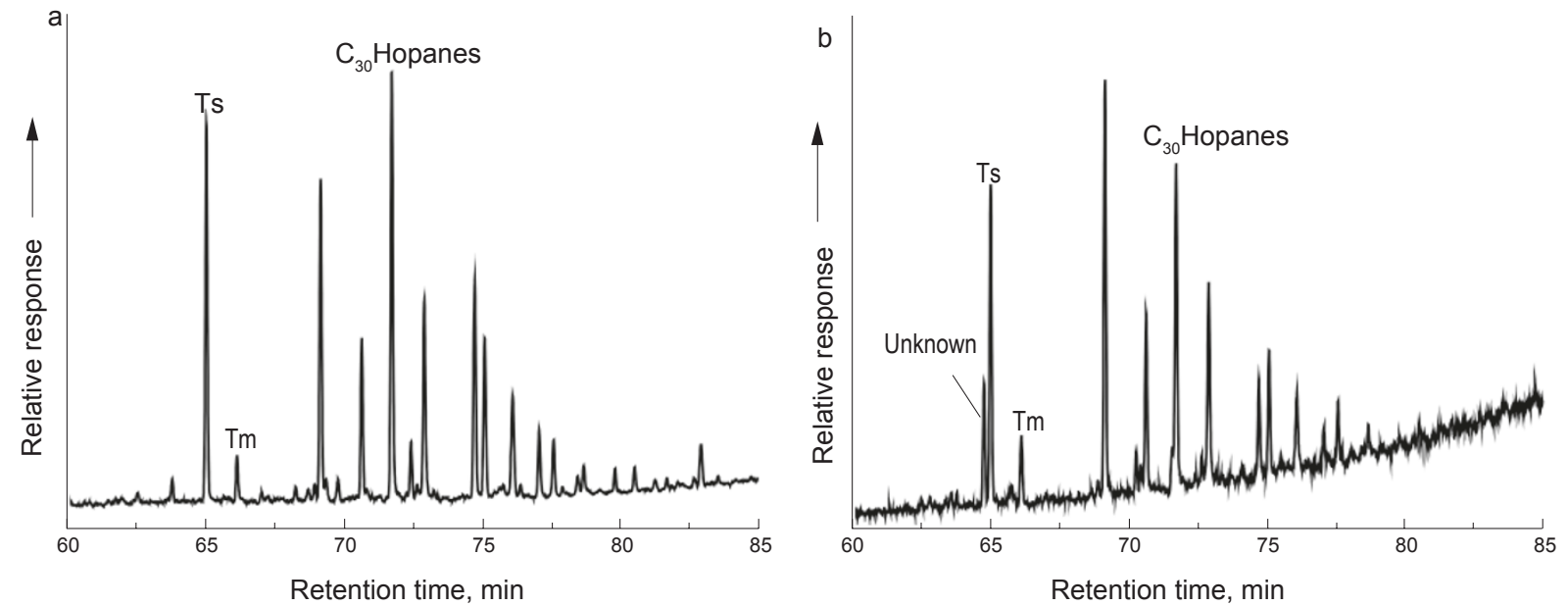

Fig. 4 M/z 191 mass chromatograph of saturated hydrocarbons from (a) SE of Fuxin coal and (b) Catalytic Hypy of Fuxin coal
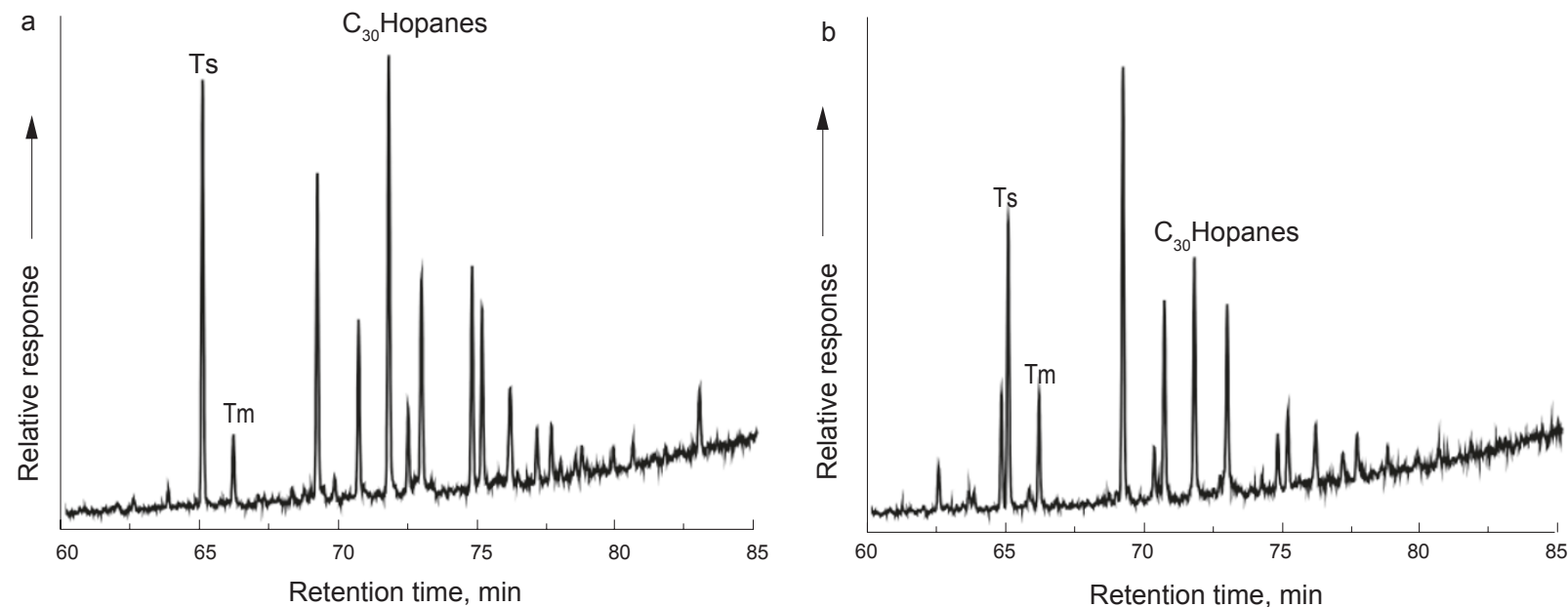

Fig. $5 \mathrm{M} / \mathrm{z} 191$ mass chromatograph of saturated hydrocarbons from (a) SE of Yingcheng coal and (b) Catalytic Hypy of Yingcheng coal

Table 3 Biomarker maturation parameters of hopanes and steranes from SE and Catalytic Hypy

\begin{tabular}{ccccccccc}
\hline Sample & Method & $\begin{array}{c}\mathrm{C} 30 \beta \alpha / \\
\mathrm{C} 30 \alpha \beta\end{array}$ & $\begin{array}{c}\mathrm{C} 29 \beta \alpha / \\
\mathrm{C} 29 \alpha \beta\end{array}$ & $\begin{array}{c}\mathrm{Ts} / \\
(\mathrm{Ts}+\mathrm{Tm})\end{array}$ & $\begin{array}{c}\mathrm{C} 29(20 \mathrm{~S}+20 \mathrm{R}): \\
\alpha \beta \beta /(\alpha \beta \beta+\alpha \alpha \alpha)\end{array}$ & $\begin{array}{c}\mathrm{C} 31 \alpha \beta 22 \mathrm{~S} / \\
(22 \mathrm{~S}+22 \mathrm{R})\end{array}$ & $\begin{array}{c}\mathrm{C} 32 \alpha \beta 22 \mathrm{~S} / \\
(22 \mathrm{~S}+22 \mathrm{R})\end{array}$ & $\begin{array}{c}\mathrm{C} 29 \alpha \alpha \alpha 20 \mathrm{~S} / \\
(20 \mathrm{~S}+20 \mathrm{R})\end{array}$ \\
\hline \multirow{2}{*}{ Fuxin coal } & $\mathrm{SE}$ & 0.48 & 0.50 & 0.89 & 0.22 & 0.57 & 0.53 & 0.26 \\
& Cat. Hypy & 0.59 & 0.40 & 0.81 & 0.17 & 0.42 & 0.38 & 0.22 \\
\hline $\begin{array}{c}\text { Yingcheng } \\
\text { coal }\end{array}$ & SE & 0.49 & 0.53 & 0.86 & 0.22 & 0.56 & 0.50 & 0.21 \\
\hline
\end{tabular}

\subsection{Catalytic mechanism of $\mathrm{MoS}_{2}$}

From the analysis above, it can be concluded that higher yields of total solvent extracts, hopanes and steranes will be produced from the catalytic Hypy with $\mathrm{MoS}_{2}$ catalyst than from the conventional Soxhlet extraction. To study the effect of dispersed catalyst on the hydropyrolysis process and its catalytic behavior, a series of control experiments of hydropyrolysis of Fuxin coal were performed with and without sulfided molybdenum as catalyst. After hydropyrolysis experiments, the total organic carbon (TOC), elements contents and hydrogen isotope values $(\delta \mathrm{D})$ of samples were determined, and the results are shown in Table 4. 
Table 4 TOC, elemental content and $\delta \mathrm{D}$ values of samples before and after hydropyrolysis

\begin{tabular}{|c|c|c|c|c|c|c|c|c|c|}
\hline Experiment & Sample & $m(\mathrm{~g})$ & TOC (\%) & $\mathrm{C}(\%)$ & $\mathrm{H}(\%)$ & $\mathrm{O}(\%)$ & N (\%) & S (\%) & $\delta \mathrm{D}(\%)$ \\
\hline \multirow{2}{*}{$\begin{array}{c}\text { Catalyst-free } \\
\text { Нypy }\end{array}$} & Coal & 3.039 & 71.24 & 73.53 & 5.68 & 13.93 & 1.23 & 1.10 & -183.93 \\
\hline & Residue & 2.215 & 75.61 & 77.04 & 4.32 & 6.94 & 1.39 & 1.02 & -6.77 \\
\hline \multirow{2}{*}{ Catalytic Hypy } & Coal & 2.812 & 71.24 & 73.53 & 5.68 & 13.93 & 1.23 & 1.10 & -183.93 \\
\hline & Residue & 1.809 & 72.99 & 72.39 & 5.09 & 6.89 & 1.48 & 2.81 & -35.47 \\
\hline
\end{tabular}

Notes: $m$ refers to the weight of solid sample before or after reaction. Mix. = the mixture of Fuxin coal and catalyst precursors before hydropyrolysis. "_-" means no detection.

Only the calculation of the decrease of sulfur content $(\Delta S)$ used the values of Mix., TOC and elements conversion were calculated according to the corresponding values of coal.

According to equations (1), (2) and (3), the TOC conversion, atomic ratios of $\mathrm{C}$ and $\mathrm{H}$ conversions $(\mathrm{C} / \mathrm{H})$ and the decrease of sulfur content $(\Delta S)$ after reaction in Hypy with and without catalyst can be calculated correspondingly.

$$
\begin{aligned}
& \text { TOC conversion (\%) }=\frac{m_{0} \times T_{0}-m \times T}{m_{0} \times T_{0}} \times 100 \\
& \mathrm{C} / \mathrm{H}=\frac{1 \times\left(m_{0} \times C_{0}-m \times C\right)}{12 \times\left(m_{0} \times H_{0}-m \times H\right)} \\
& \Delta \mathrm{S}(\mathrm{mg})=\left(m_{0} \times S_{0}-m \times S\right) \times 1000
\end{aligned}
$$

where, $T_{0}, m_{0}, C_{0}, H_{0}, S_{0}$ are the total organic carbon (TOC), weight, $\mathrm{C}, \mathrm{H}$ and $\mathrm{S}$ contents, respectively, of samples before hydropyrolysis; while $T, m, C, H, S$ refer to TOC, weight, $\mathrm{C}, \mathrm{H}$ and $\mathrm{S}$ contents, respectively, of the solid residues after reaction.

The TOC conversions in catalyst-free Hypy and $\mathrm{MoS}_{2}$ catalytic Hypy are $22.6 \%$ and $34.0 \%$ respectively, the latter much higher than the former, indicating that the presence of $\mathrm{MoS}_{2}$ can promote the hydropyrolysis of organic matter and the release of organic carbon.

Considering the condition of high $\mathrm{H}_{2}$ pressure, hydrogenation probably existed and influenced or even controlled the products generation in hydropyrolysis. To understand the influence of catalyst, it is supposed that the products generated from Hypy of Fuxin coal is of $-\mathrm{C}_{n} \mathrm{H}_{2 n}-$ or $-\mathrm{C}_{n} \mathrm{H}_{2 n} \mathrm{X}-(n=0,1, \cdots, n)$, in which $\mathrm{X}$ refers to heteroatoms such as $\mathrm{O}$ or $\mathrm{S}$. If there was no hydrogenation or the hydrogenation was so weak that its effect can be ignored, the atomic ratio of $\mathrm{C}$ and $\mathrm{H}$ conversions $(\mathrm{C} / \mathrm{H})$ should be $1: 2$ or close to $1: 2$. However, the $\mathrm{C} / \mathrm{H}$ atomic ratios in catalystfree Hypy and $\mathrm{MoS}_{2}$ catalytic Hypy were 1/1.75 and 1/1.07, respectively, apparently different each other, indicating that little hydrogenation take place in catalyst-free Hypy, and the hydropyrolysis products were mainly resulted from the thermal variation, which can promote the breaking of weak covalent bonds (C-S or some C-C) and the generation of hydrocarbons. On the contrary, hydrogenation may take place to compensate for the deficiency of hydrogen released from coal in $\mathrm{MoS}_{2}$ catalytic Hypy. Moreover, the result of $\delta \mathrm{D}$ values support this hypothesis. In catalyst-free Hypy, the fractionation of hydrogen isotope due to the thermal evolution of coal resulted in the enrichment of deuterium, with the $\delta \mathrm{D}$ value increasing from initial $-183.93 \%$ of coal sample to final $-6.77 \%$ of residue. While, in catalytic Hypy, the $\delta \mathrm{D}$ value of the residue was determined as $-86.53 \%$, the fractionation of hydrogen isotopes was suppressed because partial hydrogen was provided by $\mathrm{H}_{2}$ gas. Besides, the transfer of hydrogen from gas $\mathrm{H}_{2}$ to coal also reduced the enrichment of deuterium in the solid residue.

To further prove this result, IR spectrum detection of solid residues was performed after hydropyrolysis. As shown in Fig. 6, it can be clearly observed that for the residue from catalyst-free Hypy, the transmission spectrum at $2,800 \mathrm{~cm}^{-1}$, which represents the vibration adsorption of $-\mathrm{CH}_{2}-$ and $-\mathrm{CH}_{3}$, becomes weaker, while such a visible evolution does not appear for catalytic Hypy, compared with the original Fuxin coal. Meanwhile, the transmission spectrum near 2,350 $\mathrm{cm}^{-1}$ (representative of stretching vibration of unsaturated bonds, $-\mathrm{C} \equiv \mathrm{C}-$ and accumulated $-\mathrm{C}=\mathrm{C}-$ ) is somehow strengthened for residue from catalyst-free Hypy. Although such a change occurred it is quite weak for catalytic Hypy. These differences in IR spectrum might be attributed to hydrogenation catalyzed by dispersed molybdenum sulfide, which supplied hydrogen and hindered the occurrence of unsaturated bonds for solid organic matter during thermal evolution.

Furthermore, the compositions of saturates produced from catalyst-free and catalytic Hypy of Fuxin coal were determined by GC-MS. Fig. 7 shows the $\mathrm{m} / \mathrm{z} 83$ mass chromatograph of saturates from catalyst-free and Catalytic Hypy of Fuxin coal. From Fig. 7 it can be found: (1) Catalytic Hypy produced more high carbon number n-alkanes; (2) the presence of catalyst remarkably reduced the relative content of n-alkyl cyclohexanes in saturates. Hence, it can be confirmed that molybdenum disulfide accelerated the breaking of side chains or aliphatic chains in the coal structure and released more alkanes. In the absence of catalyst, the hydropyrolysis of coal may be approximately similar to that in conventional pyrolysis without $\mathrm{H}_{2}$. Besides, the decrease of cyclohexanes might also be attributed to the catalysis of $\mathrm{MoS}_{2}$, which may 


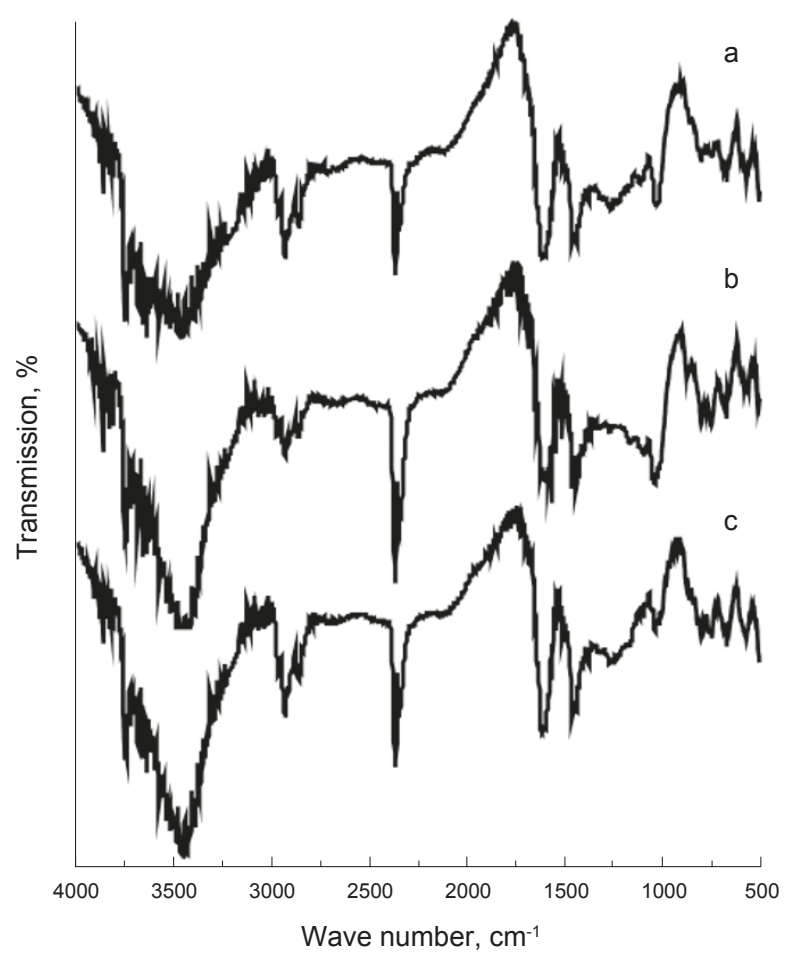

Fig. 6 Transmission infrared spectra of (a) initial coal, (b) residues from catalyst-free Hypy and (c) catalytic Hypy promote the $\beta$ scission of side chains from alkyl cyclohexanes to generate n-alkanes and methyl-cyclohexanes. As is well known, transition metal element Mo usually appears as a strong Lewis acid due to features of its orbital electrons, and its compounds, especially the disulfide, which has a layered structure and a unique charge distribution, usually exhibit excellent catalytic effects on hydrogenation of $\mathrm{CO}$ and hydrodesulfurization of organic sulfides. Consequently, to vividly describe the catalytic cracking and hydrogenation of alkyl cyclohexanes in catalytic Hypy, a mechanism for catalytic Hypy is proposed as shown in Fig. 8. The gaseous $\mathrm{H}_{2}$ was first adsorbed on the surface of $\mathrm{MoS}_{2}$ and would be dissociated into hydrogen free radical $\mathrm{H} \cdot(\mathrm{H}$ atom) when migrating to the Lewis acid sites. Simultaneously, the alkyl cyclohexanes suffered from $\beta$ scission of side chains under increasing thermal stress probably with the assistance of catalysis of $\mathrm{MoS}_{2}$, at this moment, when the cleaved radical fragments encountered $\mathrm{H} \cdot$, termination reactions immediately took place to generate smaller molecules involving alkanes and cyclohexanes, which would be ultimately desorbed and expelled from the surface of catalyst.

Actually, sulfur is usually considered as an active component favorable to the formation of hydrocarbons in pyrolysis. Lewan (1998) proposed that sulfur radicals, which can be generated from homolytic cleavage of relatively weak $\mathrm{C}-\mathrm{S}$ bond in kerogens, may promote petroleum formation

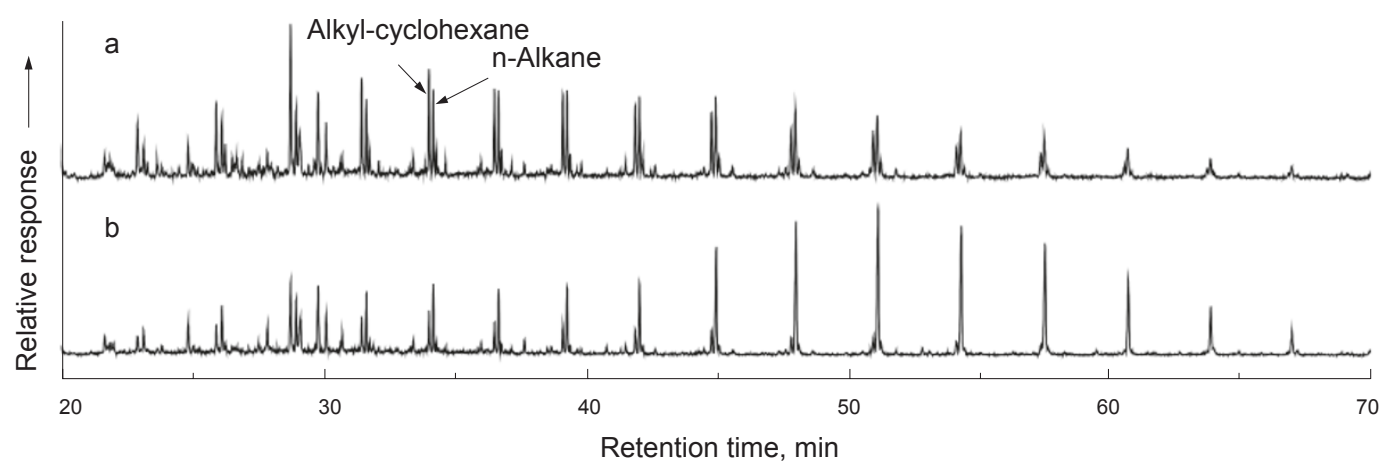

Fig. $7 \mathrm{M} / \mathrm{z} 83$ mass chromatograph of saturated hydrocarbons from (a) catalyst-free Hypy of and

(b) Catalytic Hypy of Fuxin coal

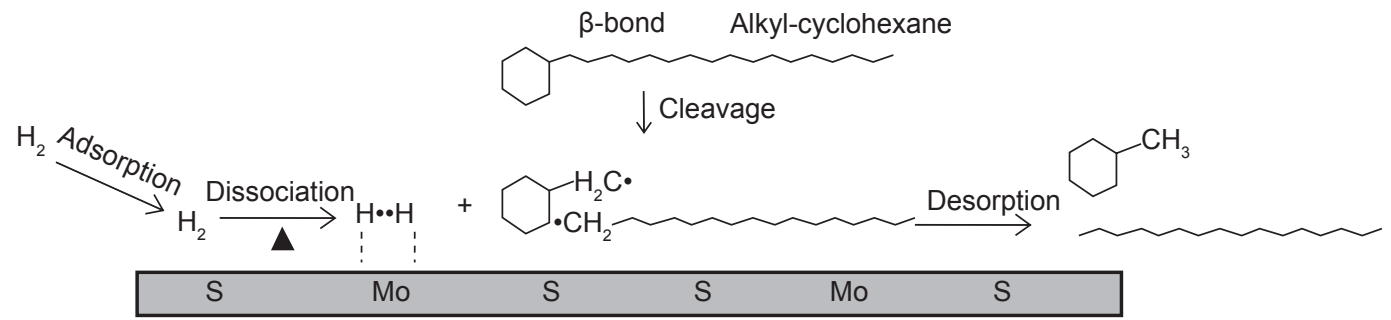

Fig. 8 Catalytic mechanism for hydrocracking of alkyl cyclohexanes

and influence the distribution of petroleum components. Otherwise, as reactive intermediates, $\mathrm{S}$ or $\mathrm{H}_{2} \mathrm{~S}$ also act as an effective initiator in thermochemical sulfate reduction (TSR) (Orr, 1974; Zhang et al, 2008). Hence, element S contained in $\mathrm{MoS}_{2}$ is supposed to have affected the hydropyrolysis of Fuxin coal. To understand whether and how $\mathrm{S}$ works, decrease of sulfur content $(\Delta S)$ between initial sample (coal or the mixture) and solid residue were calculated to be 10.8 $\mathrm{mg}$ and $44.1 \mathrm{mg}$ respectively for catalyst-free Hypy and catalytic Hypy according to equation (4). Apparently, the 
decrease of sulfur content in the catalytic process is greater than that in catalyst-free Hypy, and the reason might be that: (1) The presence of $\mathrm{MoS}_{2}$ promotes the release of sulfur from coal; (2) the catalyst precursor was decomposed to give out gaseous sulfide $\left(\mathrm{H}_{2} \mathrm{~S}\right)$. Previous studies have demonstrated that $\mathrm{MoS}_{2}$ can effectively catalyzed the desulfuration of organic sulfides and is usually used as desulfurizing agent in the petroleum industry (Boone and Ekerdt, 2000; Bevanente et al, 2002). However, the total sulfur amount of the initial coal in catalytic Hypy is only $30.9 \mathrm{mg}$, which is even lower than the decrease of sulfur content $(\Delta S)$ between initial sample and the residue. This indicates that the decomposition of the catalyst precursor should be a critical factor leading to the decrease of sulfur content $(\Delta \mathrm{S})$. As mentioned in 2.2.1, the main composition of the catalyst precursor is $\left(\mathrm{NH}_{4}\right)_{2} \mathrm{MoS}_{4}$, which will be decomposed to $\mathrm{MoS}_{2}$, as follows, when being heated in the presence of $\mathrm{H}_{2}$ :

$$
\left(\mathrm{NH}_{4}\right)_{2} \mathrm{MoS}_{4}(\mathrm{~s}) \stackrel{\Delta}{\longrightarrow} \mathrm{MoS}_{2}(\mathrm{~s})+2 \mathrm{NH}_{3}(\mathrm{~g})+\mathrm{H}_{2} \mathrm{~S}(\mathrm{~g})
$$

Moreover, the active $\mathrm{MoS}_{2}$ is likely to be reduced by $\mathrm{H}_{2}$ to generate $\mathrm{H}_{2} \mathrm{~S}$ at high temperature:

$$
\mathrm{MoS}_{2}(\mathrm{~s})+2 \mathrm{H}_{2}(\mathrm{~g}) \stackrel{\Delta}{\longleftrightarrow} \mathrm{Mo}(\mathrm{s})+2 \mathrm{H}_{2} \mathrm{~S}(\mathrm{~g})
$$

Farag et al (2009) have studied the effect of $\mathrm{H}_{2} \mathrm{~S}$ partial pressure on the catalytic hydrodesulfurization of dibenzothiophene with $\mathrm{MoS}_{2}$. They suggested that the reversible reaction (6) can lead to an increase of catalytic activity of $\mathrm{MoS}_{2}$ with increasing $\mathrm{H}_{2} \mathrm{~S} / \mathrm{H}_{2}$. Either the decomposition reaction (reaction (5)) or the reduction reaction (reaction (6)) would produce $\mathrm{H}_{2} \mathrm{~S}$ in this system. As an active compound, $\mathrm{H}_{2} \mathrm{~S}$ can readily react with hydrocarbons to generate organic sulfides, including thiols and disulfides, which would be rapidly decomposed to form free radicals and further initiate free radical reactions:

$$
\mathrm{H}_{2} \mathrm{~S}+\mathrm{HC} \rightarrow[\mathrm{R}-\mathrm{SH} \text { or R-S }-\mathrm{R}] \rightarrow \mathrm{H}_{2} \mathrm{~S}+\mathrm{R}-\mathrm{S} \cdot
$$

Based on the discussion above, the role of $\mathrm{MoS}_{2}$ catalyst can be divided into two steps: $\mathrm{H}_{2} \mathrm{~S}$.

Step 1: Free radical reactions initiated by intermediates,

Step 2: Catalytic cracking and hydrogenation of free radical organic fragments, generated in step 1 , by $\mathrm{MoS}_{2}$ catalyst.

During thermal evolution, organic matter is first converted to bitumen, which will subsequently release hydrocarbons with increasing thermal stress (Tissot and Welte, 1984). According to the reaction scheme for pyrolysis of bitumen proposed by Lewan (1997), we propose a similar reaction process for catalytic hydropyrolysis and catalyst-free hydropyrolysis of bitumen generated from kerogen or coal (Fig. 9).

Fig. 9 shows that the thermal decomposition of bitumen was significantly affected by the presence of dispersed molybdenum disulfide $\left(\mathrm{MoS}_{2}\right)$. C-C bond cross linking resulting in the formation of an insoluble residue is the

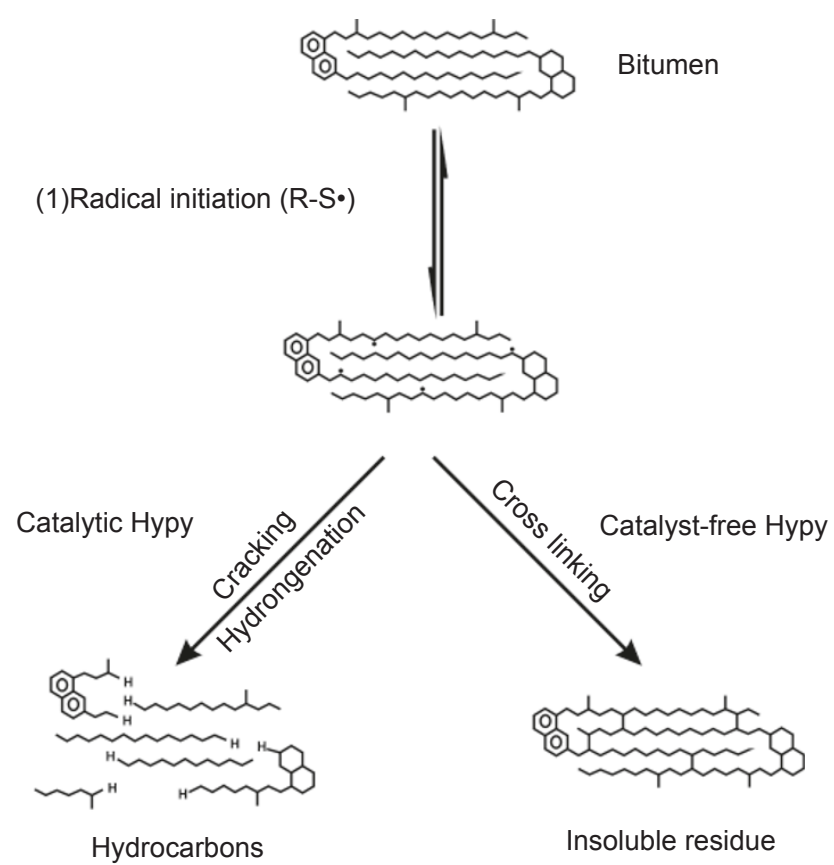

Fig. 9 Reaction process for catalytic hydropyrolysis and catalyst-free hydropyrolysis of bitumen

dominant reaction pathway in the absence of catalyst $\mathrm{MoS}_{2}$. On the contrary, due to the catalytic hydrogenation of $\mathrm{MoS}_{2}$, thermal cracking dominates the formation of hydrocarbons and the release of biomarkers in catalytic Hypy.

\section{Conclusions}

In this study, catalytic hydropyrolysis of sedimentary organic matter was performed using $\mathrm{MoS}_{2}$. Comparison of products from extracts and biomarkers indicated that catalytic Hypy can remarkably enhance the yields of total chloroform extracts, saturates, aromatics and most terpanes. Moreover, the biomarkers from Hypy show lower isomerization relative to their free counterparts, due to the protection of covalent bond linkage to kerogen or insoluble organic matter.

In addition, it is demonstrated that the presence of dispersed molybdenum sulfide catalyzed the decomposition of hydrocarbons and altered the products distribution. Most cyclohexanes underwent cracking and hydrogenation to form smaller molecules in catalytic Hypy. Ultimately, the catalytic mechanism of catalyst was addressed as follows: (1) $\mathrm{H}_{2} \mathrm{~S}$ derived from decomposition of catalyst precursor and reduction of active $\mathrm{MoS}_{2}$ in the early stage reacted with hydrocarbons to initiate free radical reactions; (2) Lewis acid sites provided by Mo have accelerated the dissociation of $\mathrm{H}_{2}$ to form $\mathrm{H} \cdot$, which is in turn abstracted by prior cleaved molecular free-radical fragments, i.e., the presence of catalyst promoted the cracking and hydrogenation reactions to form more liquid hydrocarbons, including saturates and biomarkers.

\section{Acknowledgements}

This work was financially supported by the Science and 
Technology Major project (2008A-0600) from CNPC. The authors gratefully acknowledge the two anonymous reviewers for their helpful suggestions and comments.

\section{References}

Behar F and Vandenbroucke M. Experimental determination of the rate constants of the $\mathrm{n}-\mathrm{C}$ thermal cracking at 120,400 and 800 bar: implications for high-pressure/high-temperature prospects. Energy and Fuels. 1996. 10: 932-940

Bevanente E, Santa Ana M A, Mendizábal F, et al. Interaction chemistry of molybdenum disulfide. Coordination Chemistry Reviews. 2002. 24: 87-109

Boone W P and Ekerdt J G. Hydrodesulfurization studies with a singlelayer molybdenum disulfite catalyst. Journal of Catalysis. 2000. 193: 96-102

Eglinton T I and Douglas A G. Quantitative study of biomarker hydrocarbons released from kerogens during hydrous pyrolysis. Energy and Fuels. 1988. 2: 81-88

Farag H, El-Hendawy A N A, Sakanishi K, et al. Catalytic activity of synthesized nanosized molybdenum disulfide for the hydrodesulfurization of dibenzothiophene: Effect of $\mathrm{H}_{2} \mathrm{~S}$ partial pressure. Applied Catalysis B: Environmental. 2009. 91: 189-197

Fu J M, Fan G Y, Xu J Y, et al. Application of biomarker compounds in assessment of paleoenvironments of Chinese terrestrial sediments. Geochimica. 1991. 1: 1-12 (in Chinese)

Ikenaga N, Kan-nan S, Sakoda T, et al. Coal hydroliquefaction using highly dispersed catalyst precursors. Catalysis Today. 1997. 39: 99109

Inukai Y. Hydroliquefaction of Illinois No.6 coal with petroleum atmospheric residue using oil-soluble molybdenum catalyst. Fuel Processing Technology. 1995. 43: 157-167

Kohnen M E L, Sinninghe-Damsti J S and de Leeuw J W. Biases from natural sulphurization in paleoenvironmental reconstruction based on hydrocarbon biomarker distributions. Nature. 1991. 349: 775-778

Lewan M D. Sulphur-radical control on petroleum formation rates. Nature. 1998. 391: 164-166

Lewan M D. Experiments on the role of water in petroleum formation. Geochimica et Cosmochimica Acta. 1997. 61: 3691-3723

Lockhart R S, Meredith W and Love G D. Release of bound aliphatic biomarkers via hydropyrolysis from Type II kerogen at high maturity. Organic Geochemistry. 2008. 39: 1119-1124
Love G D, Snape C E, Carr A D et al. Release of covalently-bound alkane biomarker in high yields from kerogen via catalytic hydropyrolysis. Organic Geochemistry. 1995. 23: 981-986

Meredith W, Snape C E, Carr A D, et al. The occurrence of unusual hopenes in hydropyrolysates generated from severely biodegraded oil seep asphaltenes. Organic Geochemistry. 2008. 39: 1243-1248

Orr W L. Changes in sulfur content and sulfur isotope ratios during petroleum maturation-study of Big Horn basin Paleozoic oils. American Association of Petroleum Geologists Bulletin. 1974. 50: 2295-2318

Peters K E and Moldowan J M. The biomarker guide: Interpreting molecular fossils in petroleum and ancient sediments. New Jersey: Prentice Hall. 1993

Rocha J D, Brown S D, Love G D, et al. Hydropyrolysis: a versatile technique for solid fuel liquefaction, sulfur speciation and biomarker release. Journal of Analytical and Applied Pyrolysis. 1997. 40-41: 91-103

Russell C A, Snape C E, Meredith W, et al. The potential of bound biomarker profiles released via catalytic hydropyrolysis to reconstruct basin charging history for oils. Organic Geochemistry. 2004. 35: 1441-1459

Scalan R S and Smith JE. An improved measure of the odd-even predominance in the normal alkanes of sediment extracts and petroleum. Geochimica at Cosmochimica Acta. 1970. 34: 611-620

Sharma R K, Yang J L, Zondlo J W, et al. Effect of process conditions on co-liquefaction kinetics of waste tire and coal. Catalysis Today. 1998. 40: 307-320

Shi X R, Jiao H J, Hermann K, et al. CO hydrogenation reaction on sulfided molybdenum catalysts. Journal of Molecular Catalysis A: Chemical. 2009. 312: 7-17

Snape C E, Lafferty C J, Eglinton G, et al. The potential of hydropyrolysis as a route for coal liquefaction. International Journal of Energy Research. 1994. 18: 233-242

Tis sot B P and Welte D H. Petroleum Formation and Occurrence, 2nd Edition. New York: Springer-Verlag, 1984.

Zelenski C M and Dorhout P K. Template synthesis of nearmonodisperse microscale nanofibers and nanotubes of MoS2. Journal of American Chemical Society. 1998. 120: 734-742

Zhang T W, Amrani A, Ellis G S, et al. Experimental investigation on thermochemical sulfate reduction by $\mathrm{H}_{2} \mathrm{~S}$ initiation. Geochimica et Cosmochimica Acta. 2008. 72: 3518-3530

(Edited by Zhu Xiuqin) 